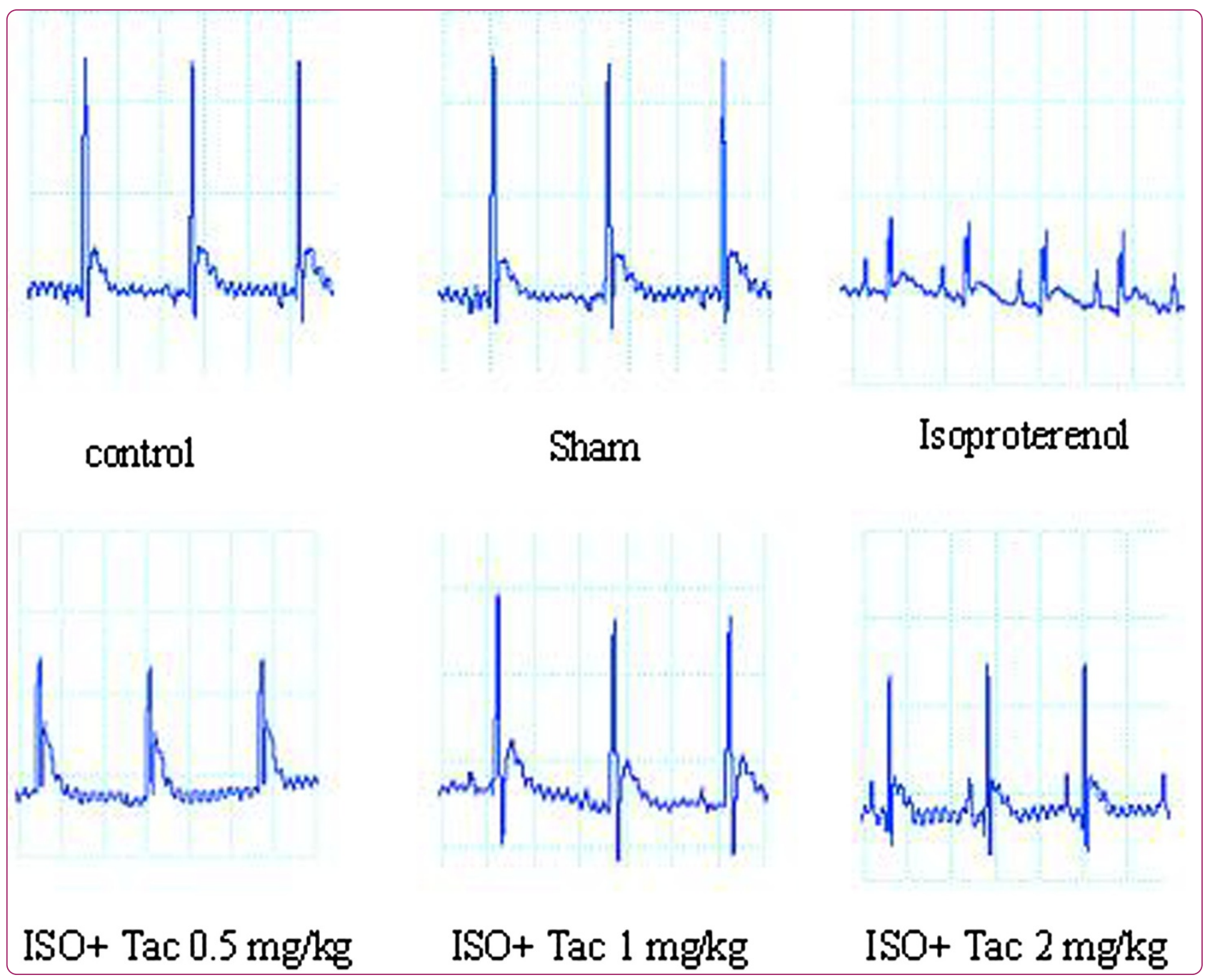

\title{
Tacrolimus ameliorates functional disturbances and oxidative stress in isoproterenol-induced myocardial infarction
}

Khorrami et al.

C Biomed Central 


\title{
Tacrolimus ameliorates functional disturbances and oxidative stress in isoproterenol-induced myocardial infarction
}

\author{
Arash Khorrami ${ }^{1,2}$, Mojtaba Hammami ${ }^{2}$, Mehraveh Garjani ${ }^{2}$, Nasrin Maleki-Dizaji ${ }^{1}$ and Alireza Garjani ${ }^{*}$
}

\begin{abstract}
Background: The inflammatory responses play a major role in the pathogenesis of acute myocardial infarction (MI). Early inhibition of inflammation may improve post MI cardiac function. The aim of this study was to investigate the effects of tacrolimus on cardiac function, hemodynamic parameters as well as histopathologic and electrocardiographic changes in isoproterenol-induced myocardial infarction.

Methods: Male Wistar rats were randomly divided into six groups of control, isoproterenol alone, tacrolimus alone, and isoproterenol plus tacrolimus $(0.5,1$ and $2 \mathrm{mg} / \mathrm{kg}$ ). Isoproterenol $(100 \mathrm{mg} / \mathrm{kg})$ was injected subcutaneously for two consecutive days to induce myocardial infarction, and simultaneously tacrolimus was administered orally twice a day for three days.

Results and conclusions: Administration of isoproterenol resulted in myocardial edema and necrosis as well as a marked reduction in the left ventricular systolic pressure (LVSP), left ventricular contractility (LVdP/dt $t_{\text {max }}$ ) and relaxation $\left(\mathrm{LV} d \mathrm{dP} / \mathrm{dt}_{\mathrm{min}}\right)$ along with a severe elevation in left ventricular end-diastolic pressure (LVEDP). Isoproterenol also elevated the ST-segment and suppressed the R-amplitude and R-R interval on ECG. It was found that all doses of tacrolimus could amend the ECG pattern and ameliorated the isoproterenol induced disturbances in cardiac function. Acute and short term treatment with tacrolimus at dose of $2 \mathrm{mg} / \mathrm{kg}$ significantly $(P<0.001)$ improved $L V d P / d t_{\text {max }}$ from $2712 \pm 82$ in myocardial infarcted rats to $4592 \pm 149 \mathrm{mmHg} / \mathrm{sec}$. Similarly, tacrolimus lowered LVEDP from $17.6 \pm 0.68 \mathrm{in} \mathrm{Ml} \mathrm{group}$ to the value of $5.6 \pm 0.22 \mathrm{mmHg}(P<0.001)$. Furthermore, tacrolimus was found to reduce malondialdehyde concentration in serum and myocardium by $50-70 \%(P<0.001)$.

The results of this study showed that acute treatment with tacrolimus, coincided with the occurrence of myocardial infarction, strongly protected the myocardium against the isoproterenol-induced myocardial infarction; where this might be due to the anti-inflammatory properties of tacrolimus.
\end{abstract}

Keywords: Tacrolimus, Myocardial infarction, Isoproterenol, Electrocardiography

\section{Background}

Cardiovascular disease (CVD), predominantly myocardial infarction, is the leading cause of death worldwide [1,2]. Reductions in the myocardial blood flow due to the coronary artery occlusion can considerably compromise the energy metabolism. Coronary artery occlusion, only as short as 5 minutes, can lead to oxidative stress and then functional abnormalities of the myocardium that persist up to 24-48 hours after reperfusion [3-5].

\footnotetext{
* Correspondence: garjania2002@yahoo.com

'Department of Pharmacology and Toxicology, Faculty of Pharmacy, Tabriz University of Medical Sciences, Tabriz, Iran

Full list of author information is available at the end of the article
}

The existing therapeutic approaches are designed to reduce the myocardial necrosis and also amendment of cardiac function after a myocardial infarction. Several studies have shown that consecutive vigorous inflammatory and immune reactions increases the generation of cytokines and oxidative stress, recruits inflammatory and $\mathrm{T}$ cells, and initiates the complement cascade $[6,7]$. The inflammatory responses induced by myocardial ischemia play a major role in the pathogenesis of acute myocardial infarction (AMI). In addition, recent studies have demonstrated that myocardial necrosis and subsequent oxidative stress trigger a cytokine cascade initiated by Tumor Necrosis Factor (TNF)- $\alpha$. These inflammatory responses 
are found to exacerbate myocardial injury and remodeling after AMI $[1,6,8]$, which lead to a progressive and irreversible myocardial damage. One of the principal interventions that exist for AMI is early inhibition of the inflammatory cycle and thus achieves a better recovery of the myocardium.

Tacrolimus (FK506) is a macrolide produced by the bacteria Streptomyces tsukubaensis. It is an immunosuppressant mainly used in organ transplantation in order to reduce the risk of graft rejection. Activation of $\mathrm{T}$ cells by allogenic antigens in transplanted tissue increases intracellular calcium concentration that contributes to the calcium-calmodulin complex formation. Calciumcalmodulin complex, in turn, activates calcineurin, a crucial phosphatase for $\mathrm{T}$ cell signaling $[9,10]$. Tacrolimus binding to the FK506 binding protein (FKBP), a respective cytoplasmic receptor, inactivates calcineurin, thereby the inflammatory response. FKBP is present in most tissues, including the myocardium. In addition to the anti-inflammatory effects of FK506-FKBP complex, it plays a critical role in modulating myocardial calcium homeostasis and rhythm regulation by stabilizing Ryanodine receptors $[7,11]$. The complex of FK506-FKBP inhibits the phosphatase activity of calcineurin and the calcium-dependent inflammatory responses. Moreover, some experimental studies have revealed that tacrolimus can effectively inhibit MAPK and PI3K-Akt signaling pathways in various inflammatory diseases [7].

Isoproterenol (ISO) is a synthetic beta-adernoceptor agonist and its subcutaneous injection induces irreversible cellular damage and ultimately myocardial infarction in rats. The acute hemodynamic and electrocardiographic changes in isoproterenol induced myocardial infarction resemble closely to those occurring in patients with myocardial infarction [12]. Therefore, the rat model of isoproterenol induced myocardial infarction offers a reliable non-invasive technique for studying the effects of various potentially cardioprotective agents [13].

The aim of the present study was to investigate the potential cardioprotective effects of tacrolimus on acute heart remodeling, hemodynamic, electrocardiographic, and biochemical changes in isoproterenol-induced myocardial infarction in rats.

\section{Materials and methods}

\section{Animals}

Male albino Wistar rats weighing between 260 and $280 \mathrm{~g}$ were used in the present study. The animals were housed in standard polypropylene cages (six per cage) under a $12 / 12 \mathrm{~h}$ light/dark cycle at a constant temperature of $20 \pm 1.8^{\circ} \mathrm{C}$ and ambient humidity of $50 \pm 10 \%$. The rats were given food and water freely. This study was performed in accordance with the Guide for the Care and Use of Laboratory Animals of Tabriz University of Medical
Sciences, Tabriz-Iran (National Institutes of Health publication No 85-23, revised 1985).

\section{Induction of acute myocardial infarction}

Isoproterenol (Sigma Co; USA) was dissolved in normal saline and injected subcutaneously to rats $(100 \mathrm{mg} / \mathrm{kg})$ for two consecutive days at an interval of 24 hours to induce acute myocardial infarction. Animals were sacrificed 48 hours after the first injection of isoproterenol [13].

\section{Experimental protocol}

The animals were randomly divided into six groups consisting of six rats each. Rats in group1 (normal control) received a subcutaneous injection of normal saline $(0.5 \mathrm{ml})$ and were left untreated for the entire experimental period. Rats in group 2 (sham) were received an oral administration of tacrolimus ( $2 \mathrm{mg} / \mathrm{kg}$; twice daily) for two consecutive days and were subcutaneously injected with normal saline. To induce myocardial infarction, rats in group 3 (MI control; ISO) were subcutaneously (SC) injected with isoproterenol $(100 \mathrm{mg} / \mathrm{kg})$ dissolved in normal saline as a vehicle $(0.5 \mathrm{ml})$ for two consecutive days at an interval of $24 \mathrm{~h}$. Rats in groups 4 to 6 were orally treated with tacrolimus at $0.5,1$ and $2 \mathrm{mg} / \mathrm{kg}$ twice daily. The treatment was started immediately prior to induction of MI (SC injection of isoproterenol) for the ensuing 2 days.

\section{Hemodynamic measurements}

About 24 to 48 hours after the last administration of drug, the animals were anesthetized by the intraperitoneal injection of a mixture of ketamine $(50 \mathrm{mg} / \mathrm{kg})$, xylazine $(30 \mathrm{mg} /$ $\mathrm{kg})$, and acepromazine $(20 \mathrm{mg} / \mathrm{kg})$. When rats did not respond to noxious stimuli, a standard limb lead (II) observed constantly during the experimental period and any changes in ECG pattern were documented. To observe the hemodynamic parameters, a ventral midline skin incision was made from the lower mandible posteriorly to the sternum $(\sim 3 \mathrm{~cm})$ and the left common carotid artery was isolated. The artery was temporary occluded toward the heart using a dieffenbach serrefines clamp (Elcon; Germany). Vannas micro iris scissors (Medi Plus; USA) was used to make a tiny incision on the carotid artery. A polyethylene cannula (Protex; OD $0.98 \mathrm{~mm}$, ID $0.58 \mathrm{~mm}$ ), coupled to a pressure transducer (Powerlab system; AD Instruments, Australia), was inserted into the artery for the recording systemic arterial blood pressure. The mean arterial blood pressure was calculated from the systolic and diastolic blood pressure traces. To assess the cardiac left ventricular function, a Mikro-Tip ${ }^{\circ}$ catheter transducer (Millar Instruments, INC) was inserted to the lumen of the left ventricle. This helped to measure the left ventricular systolic pressure (LVSP), left ventricular end-diastolic pressure (LVEDP), maximum and minimum rates of developed left ventricular pressure $\left(\mathrm{LVdP} / \mathrm{dt}_{\max }\right.$ and $\mathrm{LVdP} / \mathrm{dt}_{\text {min }}$ 
respectively) and the rate of pressure change at a fixed left ventricular pressure $(\mathrm{LVdP} / \mathrm{dt} / \mathrm{P})$. All the parameters were continuously recorded using a Powerlab system (AD Instruments, Australia) [14].

\section{Tissue weights}

Subsequent to hemodynamic measurements, the animals were euthanized, the hearts were removed, weighed, and histological examinations were done. The wet heart weight to body weight ratio was calculated to assess the degree of myocardial weight gain.

\section{Determination of lipid peroxidation in serum and myocardium}

Malondialdehyde (MDA), a thiobarbiturate reactive substance, was measured as a marker for oxidative stress in serum and myocardial homogenates using a method prescribed by Satoh [15]. To prepare the homogenates, another set of experiment $(n=6)$ including all groups was repeated and $500 \mathrm{mg}$ of heart tissues from apex were homogenized in a ratio of $1: 10$ in $0.15 \% \mathrm{KCl}$ by means of a homogenizer. Consequently the homogenates were centrifuged at $4000 \mathrm{rpm}$ at $4^{\circ} \mathrm{C}$ for $10 \mathrm{~min}$. Then $3 \mathrm{~mL}$ of phosphoric acid and $1 \mathrm{~mL}$ of TBA $0.67 \%$ were added to $250 \mu \mathrm{L}$ of supernatant of each homogenate to analyze the MDA level in tissue samples. After addition of $3 \mathrm{~mL}$ of n-Butanol to each sample, they heated in a water bath for $40 \mathrm{~min}$ and the absorbance of MDA was measured spectrophotometrically. The lipid peroxidation level expressed as nanomole MDA production per gram myocardium and nonomole per milliliter serum.

\section{Histopathological examination}

The hearts were fixed in 10\% buffered formalin. The heart tissues were embedded in paraffin, sectioned at $5 \mu \mathrm{m}$, and stained with hematoxylin and eosin (H\&E) for histologic evaluation and observed microscopically. Myocardial necrosis and edematous were evaluated in each of the four quadrants of the left ventricular cross section in each heart in the zone lying within $1.5 \mathrm{~mm}$ of the ventricular endocardium, using a morphometric point-counting procedure [16]. Two persons graded the histopathological changes as $1,2,3$, and 4 for low, moderate (focal myocyte damage or small multifocal degeneration with slight degree of inflammation), high (extensive myofibrillar degeneration and/or diffuse inflammatory process), and intensive (necrosis with diffuse inflammatory process) pathological changes, respectively.

\section{Measurements of serum TNF-a level by ELISA}

The serum level of TNF- $\alpha$ was determined using an enzyme-linked immunosorbent assay (ELISA) (Rat TNF- $\alpha$, IBL, Hamburg, Germany) according to the manufacture's instruction. Briefly, the samples were homogenized or mixed in an ice-cold solution containing $50 \mathrm{mM}$ Tris$\mathrm{HCl}, 150 \mathrm{mM} \mathrm{NaCl}, 5 \mathrm{mM}$ Sodium Pyrophosphate (NaPPi), $50 \mathrm{mM}$ NaF, $1 \mathrm{mM}$ EDTA, $1 \mathrm{mM}$.

dithiothreitol (DTT), 0.1\%SDS (w/v), 1\% TXT-100 $(\mathrm{v} / \mathrm{v})$, and protease inhibitor cocktail (Roche, Mannheim, Germany). The samples were then centrifuged twice at $10,000(\mathrm{rpm})$ for $10 \mathrm{~min}$ at $4{ }^{\circ} \mathrm{C}$. The resulting supernatants were used for assay. The concentration of the cytokines was expressed as $\mathrm{pg} / \mathrm{ml}$ of serum.

\section{Statistics}

Data were presented as mean \pm SEM. One-way ANOVA was used to make comparisons between the groups. If the ANOVA analysis indicated significant differences, StudentNewman-Keuls post test was employed to compare the mean values between the treatment groups and the control. Differences between the groups were considered significant if $\mathrm{P}<0.05$.

\section{Results}

\section{Effects of tacrolimus on electrocardiogram}

The Lead II electrocardiograms obtained from animals were shown in Figure 1. The rats were received tacrolimus alone (sham) showed normal patterns of ECG, while the rats treated with isoproterenol alone (MI group) demonstrated significant changes in ECG pattern. The changes included a marked elevation of ST segment from $95 \pm 5.2$ $\mu \mathrm{v}$ in control group to $194 \pm 14.2 \mu \mathrm{v}$ in ISO-treated group $(\mathrm{P}<0.001)$, and a reduction in $\mathrm{R}$ wave amplitude from $448 \pm 27 \mu \mathrm{v}$ in control group to $267 \pm 15 \mu \mathrm{v}$ in ISO-treated group $(\mathrm{P}<0.001)$ which both are indicative of myocardial infarction (Figure 2). Oral treatment with tacrolimus at doses of $0.5,1$ and $2 \mathrm{mg} / \mathrm{kg}$ significantly suppressed the isoproterenol-induced ST-segment elevation from $194 \pm$ $14.2 \mu \mathrm{v}$ in ISO-treated group to $169 \pm 12.7,113 \pm 8.4$ and $121 \pm 11 \mu \mathrm{v}$ in tacrolimus-treated groups, respectively.

Furthermore, treatment with all doses of tacrolimus resulted in a significant increase in the $\mathrm{R}$-amplitude $(\mathrm{P}<$ 0.001 ) as compared to the rats treated with isoproterenol alone (Figure 2).

\section{Effects of tacrolimus on hemodynamic responses}

The mean arterial pressure (MAP) was significantly decreased from $79.5 \pm 1.78 \mathrm{mmHg}$ in control group to $37 \pm$ $1 \mathrm{mmHg}$ in isoproterenol-treated group $(\mathrm{P}<0.001$; Table 1$)$. There was a significant increase in the mean arterial pressure to the value of $52 \pm 1.12,79 \pm 1.86$ and $78.2 \pm 2 \mathrm{mmHg}$, respectively, after administration of $0.5,1$ and $2 \mathrm{mg} / \mathrm{kg}$ tacrolimus.

The intraventricular pressure was measured to determine the degree of left ventricular response to isoproterenol. Isoproterenol reduced the LVSP from $112.8 \pm 2.71 \mathrm{mmHg}$ in the control group to $72.8 \pm 1.38 \mathrm{mmHg}(\mathrm{P}<0.001)$. 


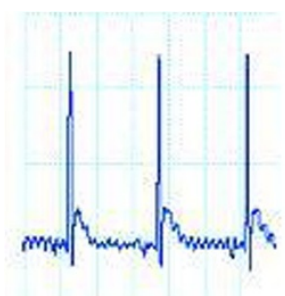

control

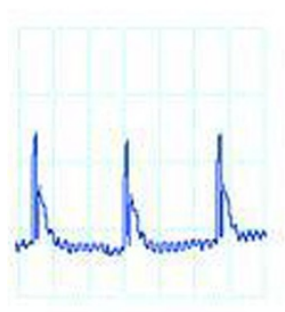

ISO+ $\operatorname{tac} 0.5 \mathrm{mg} / \mathrm{kg}$

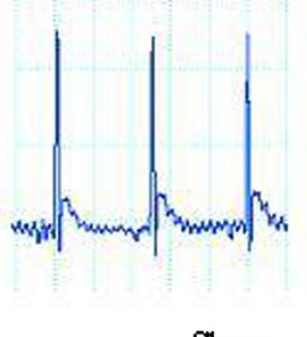

Sham



ISO+ tac $1 \mathrm{mg} k \mathrm{~kg}$
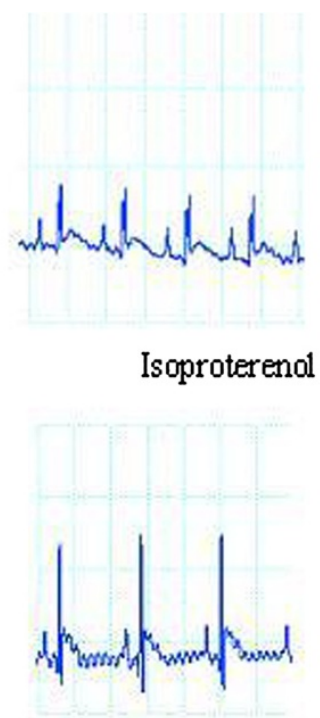

ISO+ $+\operatorname{tac} 2 \mathrm{mg} / \mathrm{kg}$

Figure 1 Effect of tacrolimus on electrocardiographic patterns and changes (recorded from limb lead II) in normal control, tacrolimus alone treated group (Sham), isoproterenol alone injected (ISO), and rats treated with tacrolimus (Tac: 0.5, 1, $2 \mathrm{mg} / \mathrm{kg}$ ).

Tacrolimus was found to increase the LVSP toward the normal value in a dose-dependent manner.

Furthermore, isoproterenol treatment leads to almost a three-fold elevation in LVEDP, which was indicative of left ventricular dysfunction. All three doses of tacrolimus remarkably $(\mathrm{P}<0.01)$ improved the left ventricular function by lowering LVEDP from $17.6 \pm 0.68 \mathrm{mmHg}$ in isoproterenol-treated rats to $10.2 \pm 0.45,6 \pm 0.24$ and $5.6 \pm 0.22$, respectively (Table 1 ).

Compared with the control group, the rats with left ventricular dysfunction (MI group) demonstrated a reduction in the value of left ventricular maximal and minimal rates of pressure ( $\mathrm{LV} \mathrm{dP} / \mathrm{dt}_{\text {max }} ; \mathrm{LV} \mathrm{dP} / \mathrm{dt}_{\text {min }} ; \mathrm{P}<0.01$; Figure 3 ) as well as a lower rate of pressure change at a fixed ventricular pressure ( $\mathrm{LV} \mathrm{dP/dt/P;} \mathrm{P}<0.05$; Table 1$)$. The mentioned indices of myocardial contractility, along with LVSP, were considerably improved by administration of all three doses of tacrolimus (Figure 3). In this regard, tacrolimus at doses of $0.5,1$ and $2 \mathrm{mg} / \mathrm{kg}$ significantly increased $\mathrm{LV} \mathrm{dP} / \mathrm{dt}_{\mathrm{Max}}$ to $3702 \pm 308(\mathrm{P}<0.05), 4484 \pm$ $318(\mathrm{P}<0.001)$ and $4592 \pm 333 \mathrm{mmHg} / \mathrm{s} \quad(\mathrm{P}<0.001)$, respectively, from $2712 \pm 181 \mathrm{mmHg} / \mathrm{s}$ in isoproterenol alone treated group. Tacrolimus had a similar effect on $\mathrm{LV} \mathrm{dP} / \mathrm{dt}_{\text {Min }}$.

\section{Effects of tacrolimus on the heart weight to body weight ratio}

The heart weight to body weight ratio $(\mathrm{mg} / \mathrm{kg})$ was determined to evaluate the amount of heart weight gain developed by the injection of isoproterenol (Figure 4). Isoproterenol injection significantly increased the ratio from $2.58 \pm 0.22$ in control group to $3.94 \pm 0.14(\mathrm{P}<0.01)$. Acute treatment with $1 \mathrm{mg} / \mathrm{kg}$ of tacrolimus resulted in a substantial $(\mathrm{P}<0.01)$ reduction in the heart to body weight ratio in comparison to the isoproterenol alone treated rats.

\section{Effects of tacrolimus on lipid peroxidation}

To determine the lipid peroxidation, MDA levels were measured in serum and myocardial homogenates. Both serum and heart MDA levels were considerably increased $(\mathrm{P}<0.001)$ in isoproterenol alone treated rats in comparison with normal control group (Table 2). However, treatment with tacrolimus significantly suppressed the rise of MDA levels of serum and myocardium $(\mathrm{P}<0.001$; Table 2$)$.

\section{Histopathological examination of the cardiac tissue}

In the control group, myocardial fibers were arranged regularly with clear striations, without any damage or necrosis in the tissue (Figure 5). Histopathological sections of the isoproterenol alone treated hearts displayed extensive hypertrophy, necrosis and increased edematous inter muscular space. Scoring the necrosis showed that all three doses of tacrolimus significantly prevented inflammatory responses. Tacrolimus at doses of $0.5,1$ and $2 \mathrm{mg} / \mathrm{kg}$ reduced isoproterenol-induced edema and necrosis by $28 \%$ $(\mathrm{P}<0.05), 35 \%(\mathrm{P}<0.01)$ and $24 \%(\mathrm{P}<0.05)$, respectively (Figure 6).

\section{Effects of tacrolimus on the level of TNF- $\alpha$ in serum after myocardial infarction}

In the present study, the effects of tacrolimus on the concentration of TNF- $\alpha$ in serum of rats with isoproterenol 


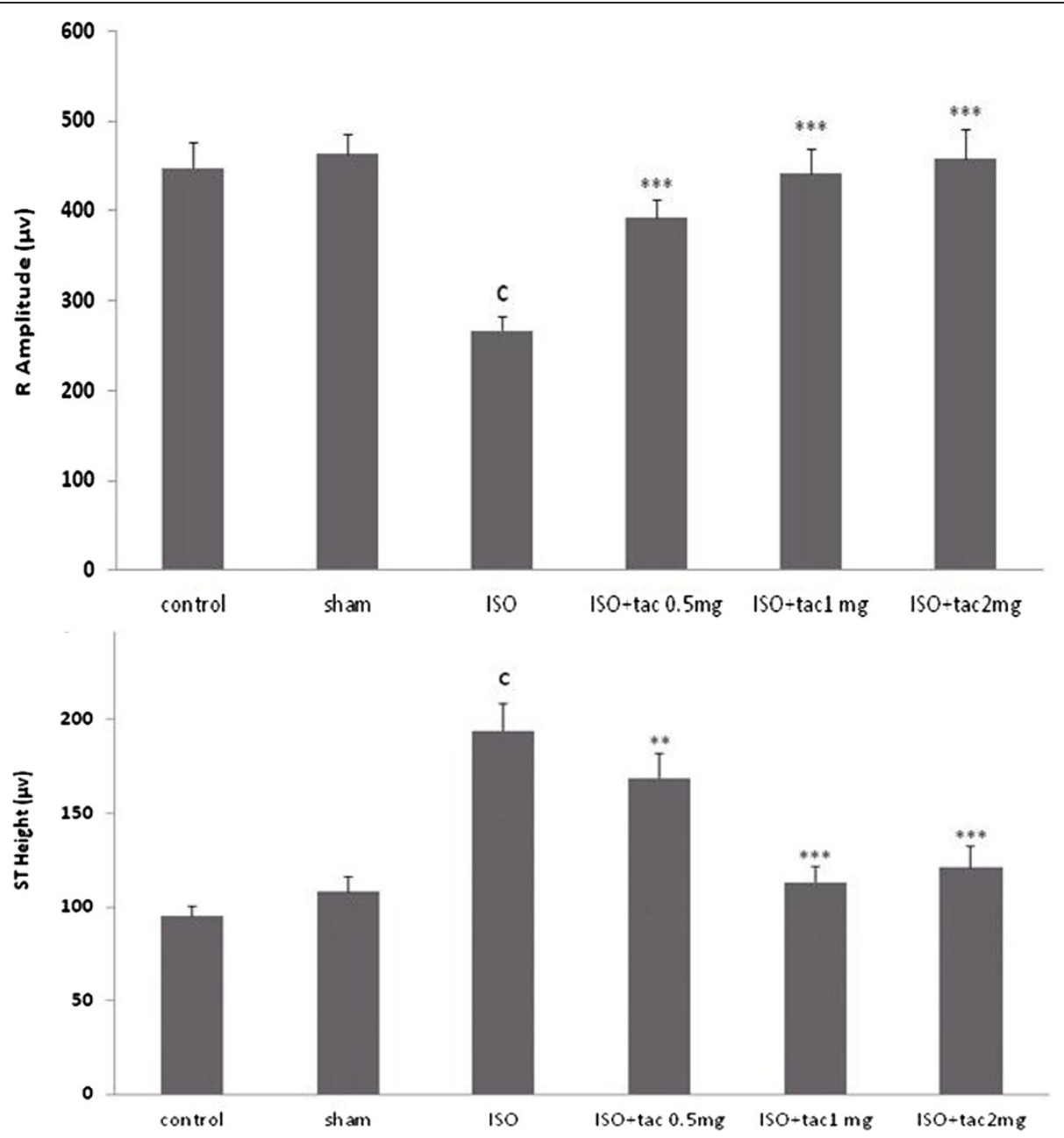

Figure 2 Effects of oral administration of tacrolimus (tac) on ST segment and R-amplitude (recorded from limb lead II). ${ }^{\mathrm{C}} \mathrm{P}<0.001$ compared to normal controls. ${ }^{* *} \mathrm{P}<0.01$ and ${ }^{* * *} \mathrm{P}<0.001$ as compared to the ISO-treated group. Data are reported as mean $\pm \operatorname{SEM}(n=6)$.

induced MI were also investigated in order to determine whether inflammatory condition in myocardium are associated with the level of pro-inflammatory cytokines. It was found that the level of TNF- $\alpha$ was profoundly increased in the isoproterenol group in comparison to the control group ( $\mathrm{P}<0.001)$ in serum (Figure 7$)$. It was observed that tacrolimus alone $(100 \mathrm{mg} / \mathrm{kg} / 12 \mathrm{~h})$ in the sham group had no effect on the level of TNF- $\alpha$ in serum. The increased level of TNF- $\alpha$ by isoproterenol was markedly decreased by treatment with tacrolimus serum. The maximal effect

Table 1 Effects of short term oral administration of tacrolimus (tac) on hemodynamic parameters in normal and isoproterenol (ISO) induced myocardial infarction rats

\begin{tabular}{|c|c|c|c|c|c|}
\hline Groups & $\begin{array}{l}\mathrm{MAP} \pm \mathrm{SEM} \\
(\mathrm{mmHg})\end{array}$ & $\begin{array}{l}\mathrm{HR} \pm \mathrm{SEM} \\
(\mathrm{bpm})\end{array}$ & $\begin{array}{l}\text { LVSP } \pm \text { SEM } \\
(\mathrm{mmHg})\end{array}$ & $\begin{array}{l}\text { LVEDP } \pm \text { SEM } \\
(\mathrm{mmHg})\end{array}$ & $\begin{array}{l}\text { LVdp/dt/p } \pm \text { SEM } \\
(1 / \mathrm{sec})\end{array}$ \\
\hline Control & $79.5 \pm 1.78$ & $197.8 \pm 3.05$ & $112.8 \pm 2.71$ & $6.3 \pm 0.21$ & $85.2 \pm 1.49$ \\
\hline Sham & $80.4 \pm 2.52$ & $216.4 \pm 6.21$ & $117.6 \pm 4.03$ & $5.4 \pm 0.36$ & $85.6 \pm 1.52$ \\
\hline ISO & $37 \pm 1.05^{c}$ & $290 \pm 7.9^{c}$ & $72.8 \pm 1.389^{c}$ & $17.6 \pm 0.68^{c}$ & $53.4 \pm 1.07^{a}$ \\
\hline ISO + tac 0.5 mg & $52 \pm 1.12^{*}$ & $247 \pm 7.35^{*}$ & $83.4 \pm 1.57$ & $10.2 \pm 0.45^{* * *}$ & $65 \pm 1.96^{*}$ \\
\hline ISO + tac $1 \mathrm{mg}$ & $79.8 \pm 1.86^{* * *}$ & $200.2 \pm 4.84^{* * *}$ & $120.6 \pm 3.76^{* * *}$ & $6 \pm 0.24^{* * *}$ & $86.6 \pm 2.07^{* * *}$ \\
\hline ISO + tac 2 mg & $78.2 \pm 2.06^{* * *}$ & $212.8 \pm 5.43^{* * *}$ & $117.8 \pm 3.24^{* * *}$ & $5.6 \pm 0.22^{* * *}$ & $83.4 \pm 1.95^{* * *}$ \\
\hline
\end{tabular}

${ }^{\mathrm{a}} \mathrm{P}<0.05,{ }^{\mathrm{C}} \mathrm{P}<0.001$ compared to normal control group. ${ }^{*} \mathrm{P}<0.05$ and ${ }^{* * *} \mathrm{P}<0.001$ as compared to the ISO-treated group. Mean arterial pressure (MAP), heart rate $(\mathrm{HR})$, left ventricular systolic pressure (LVSP), left ventricular end diastolic pressure (LVEDP), left ventricular pressure changes at a fixed pressure (LV dP/dt/P). Data are shown as mean \pm SEM $(n=6)$. 




Figure 3 The effect of oral administration of tacrolimus (tac) on the minimum and maximum left ventricular pressure (LVdP/dt $\mathrm{dax}_{\text {, }}$ LVdP/dt $\left.\mathbf{M i n}_{\text {in }}\right){ }^{{ }^{C}} \mathrm{P}<0.001$ as compared to the normal control group, ${ }^{*} \mathrm{P}<0.05$ and ${ }^{* *}{ }^{*} \mathrm{P}<0.001$ as compared to the ISO-treated group. Data are reported as mean $\pm \operatorname{SEM}(n=6)$.

was seen by $1 \mathrm{mg} / \mathrm{kg}$ of tacrolimus, where the concentration of TNF- $\alpha$ was significantly reduced from $410 \pm$ $22 \mathrm{pg} / \mathrm{mL}$ of serum to $160 \pm 14 \mathrm{pg} / \mathrm{mL} \quad(\mathrm{P}<0.001)$ (Figure 7).

\section{Discussion}

Electrocardiogram (ECG) is considered the most important clinical tool for the diagnosis of many types of myocardial infarction, especially for detection of ST segment elevation myocardial infarction (STEMI). Subcutaneous injection of isoproterenol $(100 \mathrm{mg} / \mathrm{kg})$ for two consecutive days caused ST- segment elevation and R-amplitude depression. The elevated ST-segment implies the loss of cell membrane function and the consequent potential difference between the ischemic and non-ischemic regions and the depressed R-amplitude might be due to the isoproterenol- induced myocardial edema [14]. Tacrolimus administration significantly amended the ECG pattern, indicating its protective effects on cell membrane function and electrical discharges.

Isoproterenol injection was followed by a significant decrease in arterial pressure indices, including ventricular contractility $\left(\mathrm{LVdP} / \mathrm{dt}_{\max }\right)$ and relaxation $\left(\mathrm{LVdP} / \mathrm{dt}_{\min }\right)$, as well as an increase in the left ventricular end-diastolic pressure (LVEDP). These disturbances were compatible with the hemodynamic changes occurring in the acute myocardial infarction.

The principal goal of post-MI therapy is to preserve the contractility of the heart $\left(\mathrm{LVdP} / \mathrm{dt}_{\max }\right.$ and $\left.\mathrm{LVdP} / \mathrm{dt}_{\min }\right)$ and to decrease the elevated LVEDP. Lower values of LVEDP result in improved blood flow to the subendocardial tissue, which is greatly susceptible to ischemic necrosis.

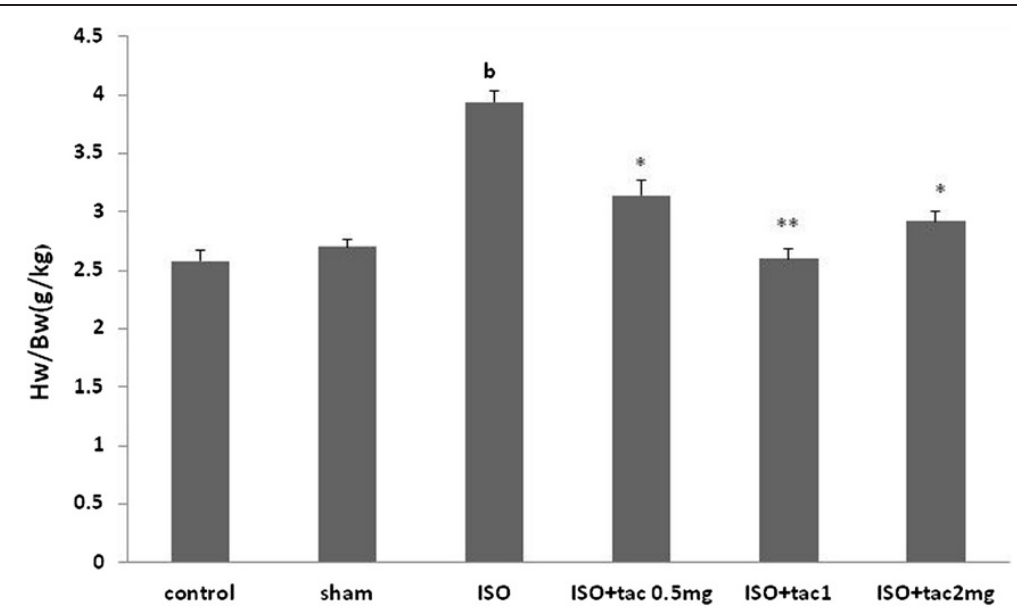

Figure 4 Effects of isoproterenol (ISO) injection as well as tacrolimus (tac) on heart weight (HW) to body weight (BW) ratio as an index of tissue edemathose in different groups. ${ }^{\mathrm{b}} \mathrm{P}<0.01$ compared to respective group in healthy animals, ${ }^{*} \mathrm{P}<0.05$ and ${ }^{*} \mathrm{P}<0.01$ as compared to isoproterenol (ISO) treated group. Data are reported as mean \pm SEM $(n=6)$. 
Table 2 The effects of acute treatment with tacrolimus (tac) on malondialdehyde (MDA) levels in the serum and heart tissue of control and rats with myocardial infarction

\begin{tabular}{lll}
\hline Groups $(\mathbf{n}=\mathbf{6})$ & MDA (nmol/mL serum) & MDA (nmol/g tissue) \\
\hline Control & $5.4 \pm 0.48$ & $2.7 \pm 0.08$ \\
sham & $4.9 \pm 0.3$ & $2.4 \pm 0.09$ \\
Isoproterenol (Iso) & $13.7 \pm 0.2^{\mathrm{a}}$ & $5.78 \pm 0.17^{\mathrm{C}}$ \\
Iso + tac $(\mathbf{0 . 5} \mathbf{~} \mathbf{~ g / k g )}$ & $7.8 \pm 1.7^{* * *}$ & $4.54 \pm 0.12^{* *}$ \\
Iso + tac (1 $\mathbf{~ g ~ g / k g ) ~}$ & $7.2 \pm 0.6^{* * *}$ & $2.9 \pm 0.06^{* * *}$ \\
Iso + tac (2 $\mathbf{~ m g / k g )}$ & $4.2 \pm 0.5^{* * *}$ & $2.5 \pm 0.09^{* * *}$ \\
\hline
\end{tabular}

${ }^{a} P<0.001,{ }^{C} P<0.01$ from respective control value; ${ }^{*} P<0.05,{ }^{* *} P<0.01$ and ${ }^{* * * P}<0.001$ as compared with ISO-treated group. Data are expressed as mean \pm $\operatorname{SEM}(n=6)$.
The results of the present study clearly demonstrated the beneficial effects of acute treatment with tacrolimus, administered concurrently with the induction of myocardial infarction, on various parameters of cardiac function. Tacrolimus was found to effectively raise the arterial blood pressure and myocardial contractility, along with decreasing the left ventricular end diastolic pressure.

Tacrolimus had more significant protective effects on the left ventricular function at the low dose of $1 \mathrm{mg} / \mathrm{kg}$ compared with the dose of $2 \mathrm{mg} / \mathrm{kg}$. This might be due to the paradoxical effects of the high dose of tacrolimus on inflammatory process and on intracellular calcium homestasis. Tacrolimus binds to FKBP and suppresses inflammatory responses. On the other hand, since FKBP plays a critical role in modulating myocardial calcium homeostasis by stabilizing ryanodine receptors, the binding may disturbs the calcium homeostasis and therefore, reverse the protective effects of the drug $[7,11]$. It seems

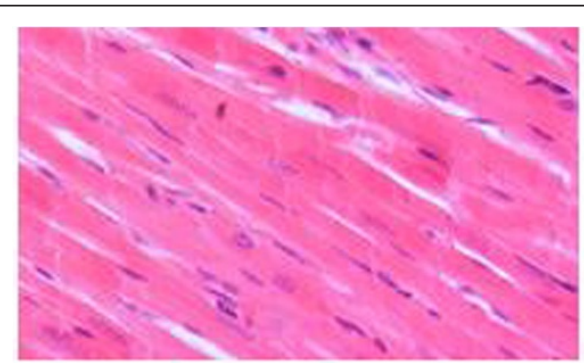

Control

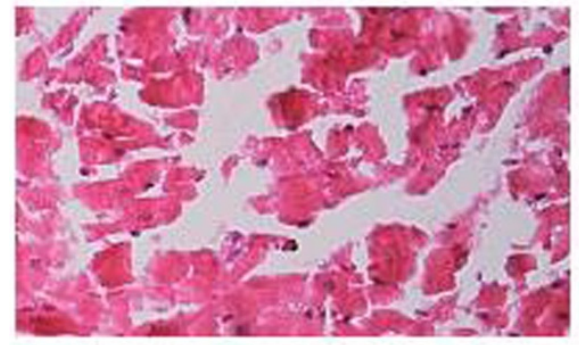

Isoproterenol



ISO + tac $1 \mathrm{mg} / \mathrm{kg}$

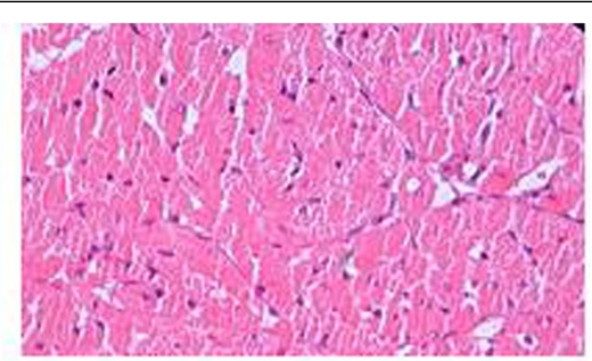

sham

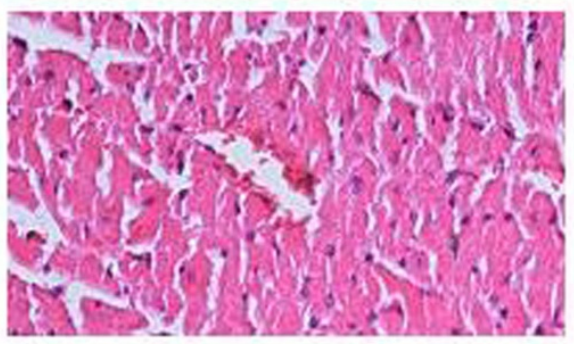

ISO $+\operatorname{tac} 0.5 \mathrm{mg} / \mathrm{kg}$

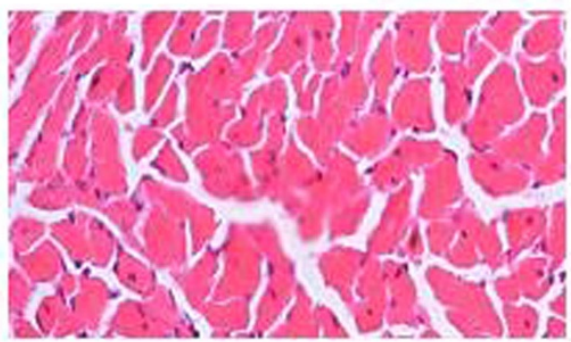

ISO $+\operatorname{tac} 2 \mathrm{mg} / \mathrm{kg}$

Figure 5 Photomicrographs of sections of rat cardiac apexes. Heart tissue of a rat treated with isoproterenol (ISO) showed intensive cardiomyocyte necrosis and increased edematous intramuscular space. Acute treatment with tacrolimus (tac) demonstrated a marked improvement. H\&E (40' magnification). 




Figure 6 Grading of histopathological changes in the rat's cardiac apex tissues. Grades 1, 2, 3, and 4 showed low, moderate, high and intensive pathological changes, respectively. ${ }^{C} \mathrm{P}<0.001$ compared to respective group in healthy animals, ${ }^{*} \mathrm{P}<0.05$ and ${ }^{*} \mathrm{P}<0.01$ as compared to isoproterenol treated group. Data are reported as mean \pm SEM $(n=6)$.

that the high dose of the drug reduces remodeling by suppressing inflammatory responses and meanwhile, it inhibits the stabilizing effects of FKBP on ryanodine receptors by binding to it [17].

The importance of oxidative stress is implicated in the pathology of myocardial infarction. There is appreciable evidence validating the direct toxic effects of free radicals on heart tissue [18]. In fact, one of the mechanisms of isoproterenol-induced myocardial infarction is to generate highly cytotoxic free radicals, as superoxide. Malondialdehyde, a product of the oxidative degradation of unsaturated fatty acids, is a biomarker of oxidative stress, and the concentration increases in response to the free radical production in myocardial infarction, and decreases by antioxidant systems $[19,20]$. The results of the present study suggest that tacrolimus possesses an in vivo antioxidant activity. Tacrolimus administration substantially reduced peroxylipid levels by $50-70 \%$ in isoproterenolinduced myocardial infarction. This reduction may relate to blunted polymorphonuclear leukocyte accumulation [21]. Tacrolimus treatment ameliorates oxidative stress augmentation which plays a pivotal role in the myocardial infarction pathology.

Histopathological examination of infarcted myocardial tissue elucidated extensive hypertrophy, subendocardial necrosis, and edema. All three doses of tacrolimus considerably attenuated the edema and necrosis in the isoproterenol-treated heart.

The heart to body weight ratio was significantly increased following isoproterenol injection. The heart weight gain might be due to water absorption and increase in protein content of muscular cells. Cardiac hypertrophy is due to increased cardiac performance. Treatment with all doses of tacrolimus markedly reduced the heart to body weight ratio. However, the drug was very effective at the low dose of $1 \mathrm{mg} / \mathrm{kg}$.

\section{Conclusions}

Limited data are available on the cardioprotective effects of tacrolimus. However, our study finds that administration of tacrolimus, simultaneous to the myocardial infarction incidence, has a remarkable protective potential

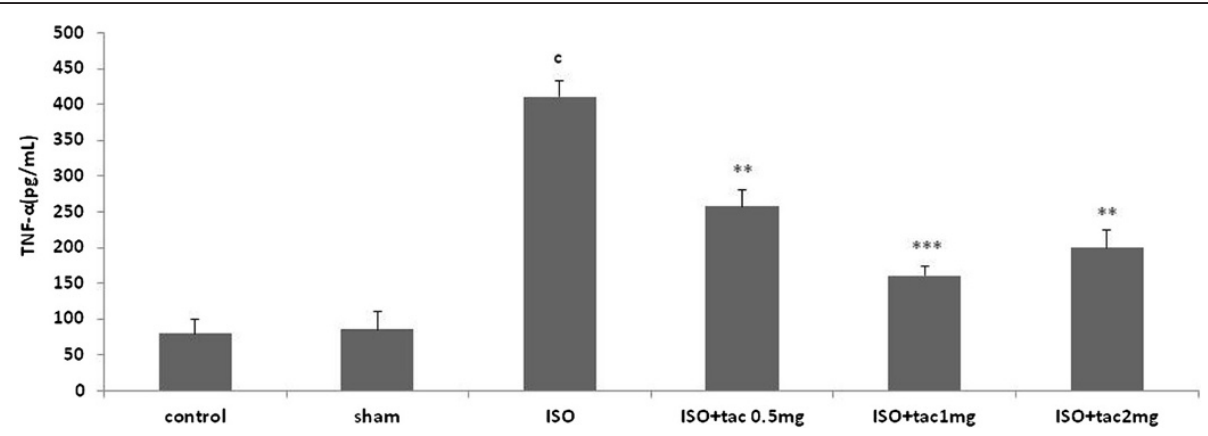

Figure 7 The effect of acute and short term treatment with tacrolimus (tac) at the doses of $0.5,1$ and $2 \mathrm{mg} / \mathrm{kg} / 12 \mathrm{~h}$ on TNFa concentration in serum. ${ }^{C} \mathrm{P}<0.001$ from respective control value; ${ }^{* *} \mathrm{P}<0.01$ and ${ }^{* * *} \mathrm{P}<0.001$ as compared with isoproterenol (ISO) injected group. Data are reported as mean $\pm \operatorname{SEM}(n=6)$. 
against damages caused by isoproterenol-induced myocardial infarction. The cardioprotective effects of acute treatment with tacrolimus are confirmed by amending electrocardiographic pattern, improvement of hemodynamic and left ventricular functions, and less histopathological damage following isoproterenol-induced myocardial infarction. It is proposed that tacrolimus exerts this cardioprotective effects through its anti-inflammatory and antioxidant properties. Although this study has provided a possible new therapeutic tool for myocardial infarction, more studies are required to elucidate the precise mechanism of tacrolimus in reversing the pathogenesis of myocardial infarction.

\section{Competing interests}

The authors declare that they have no competing interests.

\section{Authors' contribution}

MH Carried out animals grouping and handling and the biochemical experiments. AK Carried out the hemodynamic experiments. MG Accompanied Mojtaba Hammami in Ml induction and helped in preparing manuscript. NM Histopathological works and interpretations. AG Supervising and directing the project carried out the data analysis and interpretations and prepared the manuscript. All authors read and approved the fina manuscript.

\section{Acknowledgments}

The present study was supported by a grant from the Research Vice Chancellors of Tabriz University of Medical Sciences; Tabriz, Iran. This article is based on a thesis submitted for PharmD degree (No: 5/4/3419) in Faculty of Pharmacy, Tabriz University of Medical Sciences, Tabriz, Iran.

\section{Author details}

'Department of Pharmacology and Toxicology, Faculty of Pharmacy, Tabriz University of Medical Sciences, Tabriz, Iran. ${ }^{2}$ Student Research Committee, Tabriz University of Medical Sciences, Tabriz, Iran.

Received: 31 March 2014 Accepted: 21 September 2014

Published online: 14 October 2014

\section{References}

1. Xie N, Zhang W, Li J, Liang H, Zhou H, Duan W, Xu X, Yu S, Zhang H, Yi D: a-linolenic acid intake attenuates myocardial ischemia/reperfusion injury through anti-inflammatory and anti-oxidative stress effects in diabetic but not normal rats. Arch Med Res 2011, 42:171-181.

2. Colditz GA, Rimm EB, Giovannucci E, Stampfer MJ, Rosner B, Willett WC A prospective study of parental history off myocardial infarction and coronary artery disease in men. Am J Cardiol 1991, 67:933-938.

3. Neumar RW, Browns CG, Robitaille P-ML, Altschul RA: Myocardial high energy phosphate metabolism during ventricular fibrillation with total circulatory arrest. Resuscitation 1990, 19:199-226.

4. Ivan Hall R, Amos Moffitt $E$ : The effects of anaesthetics on coronary artery blood flow and myocardial metabolism: a review of studies in animals and man. Baillières Clin Anaesthesiol 1989, 3:27-46.

5. Bodi V, Sanchis J, Morales JM, Marrachelli VG, Nunez J, Forteza MJ, Chaustre F, Gomez C, Mainar L, Minana G, Rumiz E, Husser O, Noguera I, Diaz A, Moratal D, Carratala A, Bosch X, Llacer A, Chorro FJ, Viña JR, Monleon D: Metabolomic profile of human myocardial ischemia by nuclear magnetic resonance spectroscopy of peripheral blood serum: a translational study based on transient coronary occlusion models. J Am Coll Cardio/ 2012, 59:1629-1641.

6. Maekawa N, Wada H, Kanda T, Niwa T, Yamada Y, Saito K, Fujiwara H, Sekikawa K, Seishima M: Improved myocardial ischemia/reperfusion injury in mice lacking tumor necrosis factor-a. J Am Coll Cardiol 2002, 39:1229-1235.

7. Yang CH, Sheu JJ, Tsai TH, Chua S, Chang LT, Chang HW, Lee FY, Chen YL, Chung SY, Sun CK, Leu S, Yen CH, Yip HK: Effect of tacrolimus on myocardial infarction is associated with inflammation, ROS, MAP kinase and Akt pathways in mini-pigs. J Atheroscler Thromb 2013, 20:9-22.
8. Mazzone A, Cusa C, Mazzucchelli I, Vezzoli M, Ottini E, Pacifici R, Zuccaro P, Falcone C: Increased production of inflammatory cytokines in patients with silent myocardial ischemia. J Am Coll Cardiol 2001, 38:1895-1901.

9. Van Rossum H, Romijn F, Smit N, de Fijter J, Van Pelt J: Everolimus and sirolimus antagonize tacrolimus based calcineurin inhibition via competition for FK-binding protein 12. Biochem Pharmacol 2009, 77:1206-1212.

10. Chua S, Leu S, Sheu JJ, Lin YC, Chang LT, Kao YH, Yen CH, Tsai TH, Chen YL, Chang HW, Sun CK, Yip HK: Intra-coronary administration of tacrolimus markedly attenuates infarct size and preserves heart function in porcine myocardial infarction. J Inflamm 2012, 9:21-33.

11. Su Z, Sugishita K, Li F, Ritter M, Barry W: Effects of FK506 on [Ca2+]i differ in mouse and rabbit ventricular myocytes. J Pharmacol Exp Ther 2003, 304:334-341.

12. Yousefi K, Soraya H, Fathiazad F, Khorrami A, Hamedeyazdan S, Maleki-Dizaji N, Garjani A: Cardioprotective effect of methanolic extract of Marrubium vulgare L. on isoproterenol-induced acute myocardial infarction in rats. Indian J Exp Biol 2013, 51:653-660.

13. Fathiazad F, Matlobi A, Khorrami A, Hamedeyazdan S, Soraya H, Hammami M, Maleki-Dizaji N, Garjani A: Phytochemical screening and evaluation of cardioprotective activity of ethanolic extract of Ocimum basilicum L. (basil) against isoproterenol induced myocardial infarction in rats. DARU J Pharm Sci 2012, 20:87-97.

14. Garjani A, Andalib S, Biabani S, Soraya H, Doustar Y, Garjani A, Maleki-Dizaji N: Combined atorvastatin and coenzyme Q10 improve the left ventricular function in isoproterenol-induced heart failure in rat. Eur J Pharmacol 2011 666:135-141.

15. Satoh K: Serum lipid peroxide in cerebrovascular disorders determined by a new colorimetric method. Clinica Chimica Acta 1978, 90:37-43.

16. Benjamin IJ, Jalil JE, Tan LB, Cho K, Weber KT, Clark WA: Isoproterenolinduced myocardial fibrosis in relation to myocyte necrosis. Circ Res 1989 65:657-670

17. Shawn D, St. P, Adyr AM, David CM: Effects of tacrolimus on ischemiareperfusion injury. Liver Transp/ 2003, 9:105-116.

18. Rona G: Catecholamine cardiotoxicity. J Mol Cell Cardiol 1985, 7:291-306.

19. Radovanovic S, Savic-Radojevic A, Pljesa-Ercegovac M, Djukic T, Suvakov S, Krotin M, Simic DV, Matic M, Radojicic Z, Pekmezovic T, Simic T: Markers of oxidative damage and antioxidant enzyme activities as predictors of morbidity and mortality in patients with chronic heart failure. J Card Fail 2012, 18:493-501.

20. Ho E, Karimi Galougahi K, Liu C-C, Bhindi R, Figtree GA: Biological markers of oxidative stress: applications to cardiovascular research and practice. Redox Biol 2013, 1:483-491.

21. Squadrito F, Altavilla D, Squadrito G, Saitta A, Deodato B, Arlotta M, Minutoli L, Quartarone C, Ferlito M, Caputi AP: Tacrolimus limits polymorphonuclear leucocyte accumulation and protects against myocardial ischaemia-reperfusion injury. J Mol Cell Cardiol 2000, 32:429-440.

doi:10.1186/s40199-014-0068-3

Cite this article as: Khorrami et al:: Tacrolimus ameliorates functional disturbances and oxidative stress in isoproterenol-induced myocardial infarction. DARU Journal of Pharmaceutical Sciences 2014 22:68.

\section{Submit your next manuscript to BioMed Central and take full advantage of:}

- Convenient online submission

- Thorough peer review

- No space constraints or color figure charges

- Immediate publication on acceptance

- Inclusion in PubMed, CAS, Scopus and Google Scholar

- Research which is freely available for redistribution 